\title{
Effects of telmisartan therapy on interleukin- 6 and tumor necrosis factor-alpha levels: a meta-analysis of randomized controlled trials
}

\author{
Hisato Takagi, Yusuke Mizuno, Hirotaka Yamamoto, Shin-nosuke Goto and Takuya Umemoto for the ALICE \\ (All-Literature Investigation of Cardiovascular Evidence) Group
}

A recent meta-analysis of randomized head-to-head trials suggests that therapy with telmisartan, an angiotensin II receptor blocker (ARB) and partial agonist of peroxisome proliferator-activated receptor-gamma, may increase adiponectin levels more strongly than other ARB therapies. Therefore, telmisartan would be expected to reduce interleukin-6 (IL-6) or tumor necrosis factor-alpha (TNF- $\alpha$ ). To determine whether telmisartan reduces IL- 6 or TNF- $\alpha$, we performed the first meta-analysis of randomized controlled trials of telmisartan therapy. MEDLINE, EMBASE and the Cochrane Central Register of Controlled Trials were searched through November 2011. Eligible studies were prospective randomized controlled trials of telmisartan vs. unrestricted control therapy reporting IL- 6 or TNF- $\alpha$ levels as an outcome. For each study, data regarding percent changes from baseline to final IL-6 or TNF- $\alpha$ levels in both the telmisartan and control groups were used to generate standardized mean differences (SMDs) and $95 \%$ confidence intervals (Cls). Nine reports of randomized trials enrolling a total of 645 patients were identified. Pooled analysis of seven and five trials demonstrated a statistically significant reduction in percent changes of IL-6 (fixed-effects SMD, $-0.385 ; 95 \% \mathrm{Cl},-0.581$ to $-0.189 ; \boldsymbol{P}<0.001 ; P$ for heterogeneity $=0.073$ ) and TNF- $\alpha$ levels (random-effects SMD, $-0.627 ; 95 \% \mathrm{Cl},-0.945$ to $-0.308 ; P<0.001 ; P$ for heterogeneity $=0.029$ ) with telmisartan relative to control therapy, respectively. In conclusion, based on a meta-analysis of nine randomized controlled trials, telmisartan therapy is likely effective in reducing IL- 6 and TNF- $\alpha$ levels.

Hypertension Research (2013) 36, 368-373; doi:10.1038/hr.2012.196; published online 13 December 2012

Keywords: interleukin-6; meta-analysis; telmisartan; tumor necrosis factor-alpha

\section{INTRODUCTION}

Adiponectin is an abundant adipocyte-derived protein with wellestablished anti-atherogenic, insulin-sensitizing and anti-inflammatory properties. ${ }^{1}$ Interleukin-6 (IL-6) is an important adipocytokine linking obesity to vascular disease ${ }^{2}$ and a regulator of hepatic C-reactive protein (CRP) production. ${ }^{3}$ Adiponectin expression may be negatively regulated by IL- 6 in adipose tissue. ${ }^{2}$ Tumor necrosis factor-alpha (TNF- $\alpha$ ), another adipocytokine, is thought to be involved in the induction of insulin resistance in obesity and may also have a role in the regulation of hepatic CRP synthesis and induction of IL-6 expression., ${ }^{3,4}$ Adiponectin may indirectly inhibit IL-6 and CRP expression through its ability to inhibit the production of TNF- $\alpha .^{2}$ A meta-analysis ${ }^{5}$ points to a clear increase in adiponectin serum levels after the administration of thiazolidinedione, a peroxisome proliferator-activated receptor-gamma (PPAR- $\gamma)$ agonist. $^{6}$

Telmisartan, an angiotensin II receptor blocker (ARB), can act as a partial agonist of PPAR- $\gamma{ }^{7}$ The results of our recent meta-analysis ${ }^{8}$ of randomized head-to-head trials suggest that telmisartan therapy may increase adiponectin levels more strongly than other ARB therapy.
Therefore, telmisartan would be expected to reduce IL- 6 or TNF- $\alpha$. Although a number of randomized controlled trials of telmisartan therapy for the reduction of IL- 6 or TNF- $\alpha$ levels have been published to date, the results have been inconclusive. To determine whether telmisartan reduces IL- 6 or TNF- $\alpha$, we performed the first metaanalysis of randomized controlled trials of telmisartan therapy.

\section{METHODS}

\section{Search strategy}

All prospective randomized controlled trials of telmisartan therapy were identified using a 2-level search strategy. First, public domain databases including MEDLINE, EMBASE and the Cochrane Central Register of Controlled Trials were searched through November 2011 using Web-based search engines (PubMed and OVID). Second, relevant studies were identified through a manual search of secondary sources, including the references of initially identified articles and a search of reviews and commentaries. All references were downloaded for consolidation, elimination of duplicates and further analysis. Keywords included telmisartan; interleukin, IL, tumor necrosis factor, or TNF; and randomized, randomised, randomly, or randomization. 


\section{Study selection and data abstraction}

Studies considered for inclusion met the following criteria: the design was a prospective randomized controlled clinical trial; the study population consisted of unrestricted patients; the patients were randomly assigned to telmisartan $v s$. unrestricted control therapy (including placebo and no treatment); and the outcomes included IL- 6 or TNF- $\alpha$ levels. Data regarding detailed inclusion criteria, duration of follow-up, and IL- 6 or TNF- $\alpha$ levels were abstracted (as available) from each individual study.

\section{Statistical analysis}

For each study, data regarding percent changes from baseline to final IL-6 or TNF- $\alpha$ levels in both the telmisartan and control groups were used to generate standardized mean differences (SMDs) and 95\% confidence intervals (CIs). When standard deviations (SDs) were unavailable and where only baseline and final IL- 6 or TNF- $\alpha$ levels were reported, missing SDs were imputed and changes from baseline to final IL- 6 or TNF- $\alpha$ levels were obtained according to the Cochrane Handbook, ${ }^{9}$ respectively. As suggested by Follmann et al. ${ }^{10}$ we assumed a correlation coefficient of 0.5 between the baseline and final values and equal variances during the trial and between the telmisartan and control groups. Study-specific estimates were separately combined for IL- 6 and TNF- $\alpha$ using inverse variance-weighted averages of logarithmic SMDs in both fixedand random-effects model. Between-study heterogeneity was analyzed by means of standard $\chi^{2}$-tests. Where no significant statistical heterogeneity was identified, the fixed-effects estimate was used preferentially as the summary measure. Sensitivity analyses were performed to assess the contribution of each study to the pooled estimate by excluding individual trials one at a time and recalculating the pooled SMD estimates for the remaining studies. Publication bias was assessed graphically using a funnel plot and mathematically using an adjusted rank-correlation and linear regression test. All analyses were conducted using Comprehensive Meta-Analysis version 2 software (Biostat, Englewood, NJ, USA).

\section{RESULTS}

\section{Search results}

Our comprehensive search identified 12 prospective randomized controlled clinical trials of telmisartan vs. control therapy. ${ }^{11-22} \mathrm{We}$ excluded trials by Nagel et al..$^{20}$ and Wohl et al. ${ }^{21}$ that reported only final IL- 6 or TNF- $\alpha$ levels. A trial by Cadeddu et al. ${ }^{22}$ was also eliminated because it enrolled quite different patients with histologically confirmed tumors at different sites, previously untreated, to be treated with an epirubicin-based chemotherapy regimen. In total, our meta-analysis included data on 645 patients from the remaining 9 trials $^{11-19}$ that were randomized to therapy with telmisartan or control (Table 1).

\section{Qualitative findings}

Bähr et al. ${ }^{11}$ conducted a 14-week, randomized, double-blind, placebocontrolled, 2-center study with 80 and $160 \mathrm{mg}$ per day telmisartan treatment in patients with metabolic syndrome. In this low-risk patient population, telmisartan treatment did not significantly affect serum IL-6 levels. Derosa et al. ${ }^{12}$ evaluated type 2 diabetic patients with metabolic syndrome, all of whom had been diabetic for at least 6 months and took a fixed dose of rosiglitazone, and in all of whom glycemic control by the maximum tolerated dietary changes and maximum tolerated dose of oral hypoglycemic agents had been attempted and failed. The authors administered telmisartan or irbesartan in a randomized, controlled, double-blind, clinical manner. Significant decreases in TNF- $\alpha$ levels were observed after 6 months in the telmisartan group and after 12 months in both groups.

Hong et al. ${ }^{13}$ compared the effects of telmisartan and valsartan after sirolimus-eluting stent implantation in a prospective, randomized, single-blinded, 8-month follow-up study that included hypertensive patients with significant coronary artery stenosis. After 8 months of follow-up, only the telmisartan group showed significant decreases in IL-6 and TNF- $\alpha$. Hong et al. ${ }^{14}$ compared the effects of telmisartan and valsartan after stenting in a prospective, randomized, 8-month follow-up study that included hypertensive type 2 diabetes with significant coronary stenosis. The decreases from baseline in IL-6 and TNF- $\alpha$ levels were significantly greater in the telmisartan group at 8 months.

In a prospective, randomized study, Huang et al. ${ }^{15}$ investigated the effects of telmisartan in patients with hypertension and obesity treated with telmisartan or losartan for 16 weeks. The levels of serum TNF- $\alpha$ only improved in the telmisartan group. In a prospective double-blind study by Link et al. ${ }^{16}$ patients with hypertension and coronary artery disease were treated with either telmisartan or a placebo for 12 weeks. As expected for normal ranges, TNF- $\alpha$ and IL- 6 remained unchanged in both the placebo and telmisartan groups.

Nakamura et al. ${ }^{17}$ compared the effects of telmisartan and amlodipine in untreated hypertensive chronic kidney disease patients with moderate renal insufficiency randomly assigned to receive telmisartan or amlodipine for 12 months. Plasma levels of IL-6 decreased more strikingly in the telmisartan group than in the amlodipine group. Nakamura et al. ${ }^{18}$ investigated the effect of telmisartan vs. enalapril in patients with hypertensive autosomal dominant polycystic kidney disease with good renal function randomly assigned to telmisartan or enalapril. Although serum IL-6 levels significantly decreased after treatment in both groups, the decrease in serum IL-6 was significantly greater in the telmisartan group than in the enalapril group at 6 and 12 months.

Nakayama et al. ${ }^{19}$ compared the effects of olmesartan and telmisartan in an open-label, prospective, crossover study to which early-stage type- 2 diabetes patients with hypertension who had been treated with valsartan for at least 8 weeks were recruited. At study entry, valsartan was switched to olmesartan or telmisartan and administered for 8 weeks, and the drugs were then switched and treatment was continued for another 8 weeks. The olmesartan treatment resulted in a more significant decrease in serum IL-6. Despite the noted heterogeneity in design between the trials, there was sufficient similarity between the populations and the hypotheses to merit the inclusion of all 11 trials in the quantitative meta-analysis.

\section{Quantitative findings}

Pooled analysis of seven and five trials demonstrated a statistically significant reduction in percent changes of IL-6 (fixed-effects SMD, $-0.385 ; 95 \% \mathrm{CI},-0.581$ to -0.189 ; $P<0.001$; random-effects SMD, $-0.363 ; 95 \% \quad \mathrm{CI}, \quad-0.658$ to $-0.069 \quad P=0.016 ; \quad P$ for heterogeneity $=0.073$; Figure 1) and TNF- $\alpha$ levels (random-effects SMD,$-0.627 ; 95 \% \mathrm{CI},-0.945$ to $-0.308 ; P<0.001$; fixed-effects SMD, $-0.688 ; 95 \%$ CI, -0.869 to $-0.506 ; \quad P<0.001 ; \quad P$ for heterogeneity $=0.029$; Figure 2 ) with telmisartan relative to control therapy, respectively. To assess the impact of qualitative heterogeneity in trial design and patient selection on the pooled effect estimate, we performed several sensitivity analyses. The exclusion of any single trial from the analysis did not substantively alter the overall result of our analysis for IL-6 (Figure 3) or TNF- $\alpha$ (Figure 4).

In the excluded study by Cadeddu et al., ${ }^{22}$ serum levels of IL- 6 rose significantly in the placebo arm at 7 days after reaching the epirubicin dose of $200 \mathrm{mg} \mathrm{m}^{-2} \quad\left(68.8 \pm 52.6\right.$ vs. $\left.31 \pm 8.8 \mathrm{pg} \mathrm{ml}^{-1} ; \quad P<0.05\right)$ but remained unchanged in the telmisartan arm $(27.7 \pm 18.1$ vs. $26 \pm 18.8 \mathrm{pg} \mathrm{ml}^{-1}$ ). The same trend was shown by TNF- $\alpha$ serum levels, which increased significantly at 7 days after reaching the epirubicin dose of $200 \mathrm{mg} \mathrm{m}^{-2}$ in the placebo arm $(47.1 \pm 4.6$ vs. $\left.30.1 \pm 9 \mathrm{pg} \mathrm{ml}^{-1}\right)$ but not in the telmisartan arm $(22.3 \pm 10.6$ 


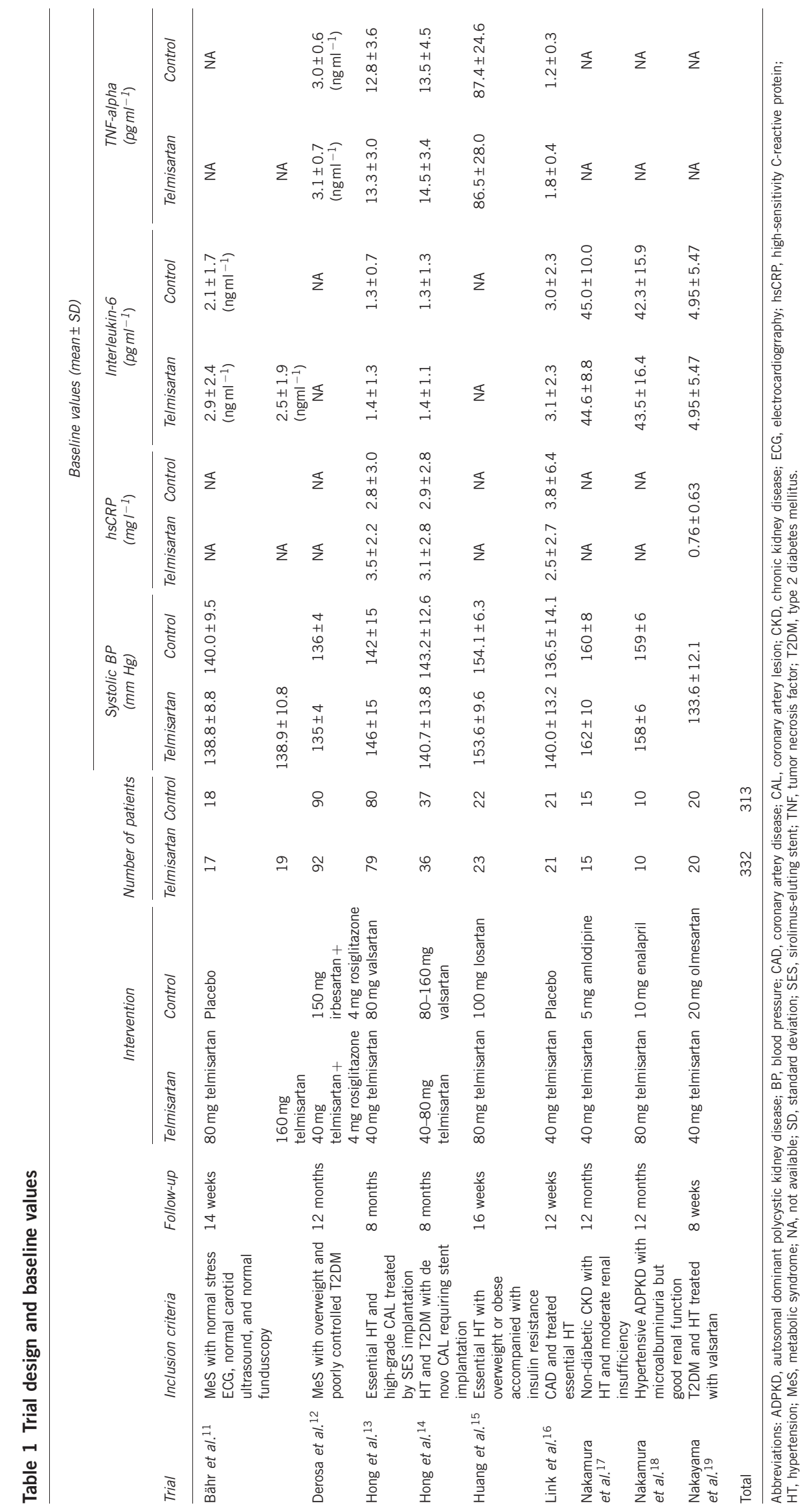




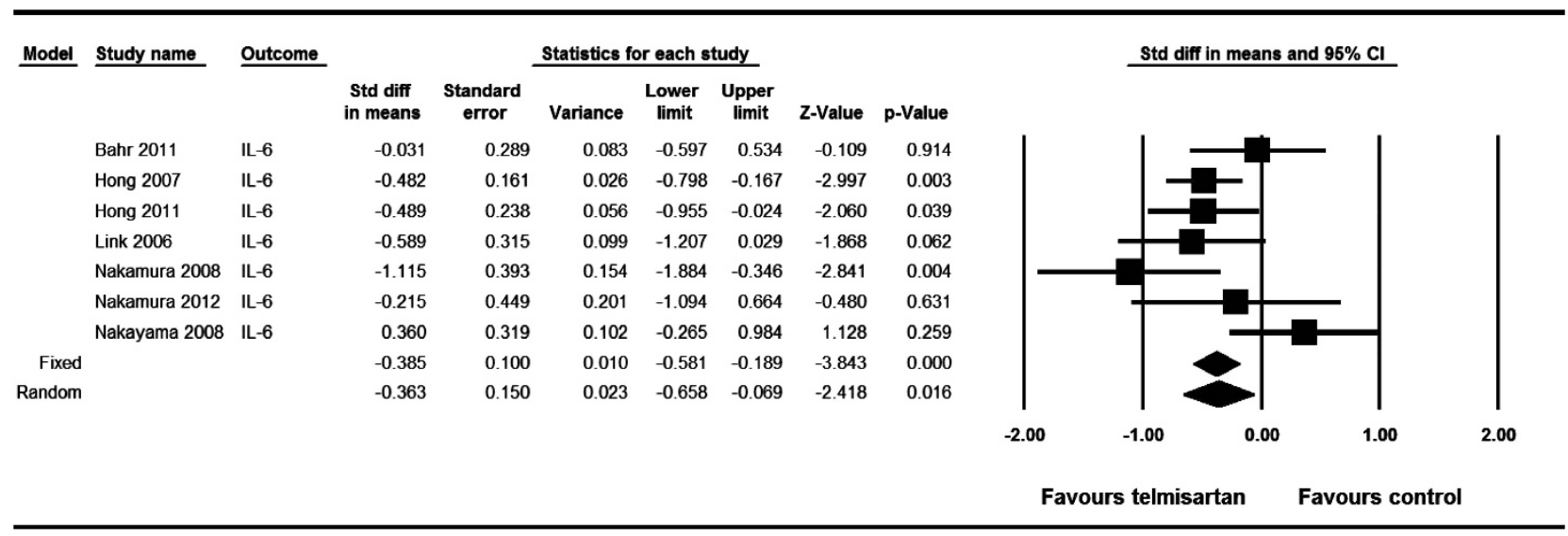

Figure 1 Percent changes in interleukin-6 (IL-6) levels among patients randomized to telmisartan vs. control therapy. $\mathrm{Cl}$, confidence interval.

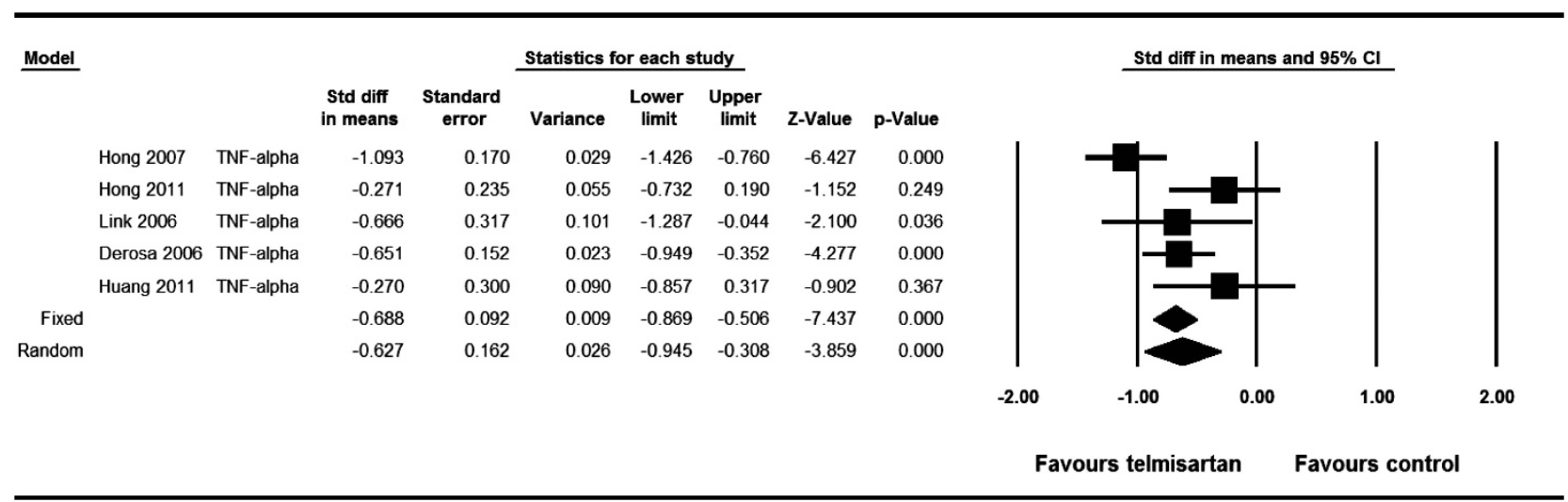

Figure 2 Percent changes in tissue necrosis factor-alpha (TNF- $\alpha$ ) levels among patients randomized to telmisartan vs. control therapy. Cl, confidence interval.

\begin{tabular}{|c|c|c|c|c|c|c|c|c|c|c|c|c|}
\hline \multirow[t]{2}{*}{$\underline{\text { Study name }}$} & \multirow[t]{2}{*}{ Outcome } & \multicolumn{7}{|c|}{ Statistics with study removed } & & \multirow{2}{*}{\multicolumn{2}{|c|}{$\begin{array}{l}\text { Std diff in means }(95 \% \\
\text { Cl) with study removed }\end{array}$}} & \\
\hline & & Point & $\begin{array}{l}\text { Standard } \\
\text { error }\end{array}$ & Variance & $\begin{array}{l}\text { Lower } \\
\text { limit }\end{array}$ & $\begin{array}{l}\text { Upper } \\
\text { limit }\end{array}$ & Z-Value & $\mathrm{p}$-Value & & & & \\
\hline Bahr 2011 & IL-6 & -0.433 & 0.107 & 0.011 & -0.642 & -0.224 & -4.057 & 0.000 & & & & \\
\hline Hong 2007 & IL-6 & -0.323 & 0.128 & 0.016 & -0.574 & -0.072 & -2.526 & 0.012 & & & & \\
\hline Hong 2011 & IL-6 & -0.362 & 0.110 & 0.012 & -0.579 & -0.146 & -3.280 & 0.001 & & & & \\
\hline Link 2006 & IL-6 & -0.362 & 0.106 & 0.011 & -0.569 & -0.155 & -3.427 & 0.001 & & & & \\
\hline \multicolumn{2}{|c|}{ Nakamura 2008IL-6 } & -0.334 & 0.104 & 0.011 & -0.537 & -0.131 & -3.225 & 0.001 & & & & \\
\hline \multicolumn{2}{|c|}{ Nakamura 2012 IL-6 } & -0.394 & 0.103 & 0.011 & -0.595 & -0.192 & -3.832 & 0.000 & & & & \\
\hline \multirow{2}{*}{\multicolumn{2}{|c|}{ Nakayama 2008IL-6 }} & -0.466 & 0.105 & 0.011 & -0.673 & -0.260 & -4.421 & 0.000 & & & & \\
\hline & & -0.385 & 0.100 & 0.010 & -0.581 & -0.189 & -3.843 & 0.000 & & & & \\
\hline & & & & & & & & & -1.00 & -0.50 & 0.50 & 1.00 \\
\hline & & & & & & & & & \multicolumn{2}{|c|}{ Favours telmisartan } & ours co & \\
\hline
\end{tabular}

Figure 3 One-study-removed meta-analysis of percent changes in interleukin-6 (IL-6) levels among patients randomized to telmisartan vs. control therapy. $\mathrm{Cl}$, confidence interval.

vs. $23.5 \pm 5.5 \mathrm{pg} \mathrm{ml}^{-1}$ ). When these results were added to a primary meta-analysis, pooled analysis of eight and six trials demonstrated a statistically significant reduction in changes of IL-6 (random-effects SMD, $-0.435 ; 95 \% \mathrm{CI},-0.725$ to $-0.146 ; \quad P=0.003 ; \quad P$ for heterogeneity $=0.040$ ) and TNF- $\alpha$ levels (random-effects SMD,
$-0.780 ; \quad 95 \% \quad$ CI, $\quad-1.169$ to $-0.391 ; \quad P<0.001 ; \quad P \quad$ for heterogeneity $=0.001$ ) with telmisartan relative to control therapy, respectively.

Two trials ${ }^{20,21}$ were eliminated from the present meta-analysis because of unavailable percent changes in IL- 6 or TNF- $\alpha$ levels. 


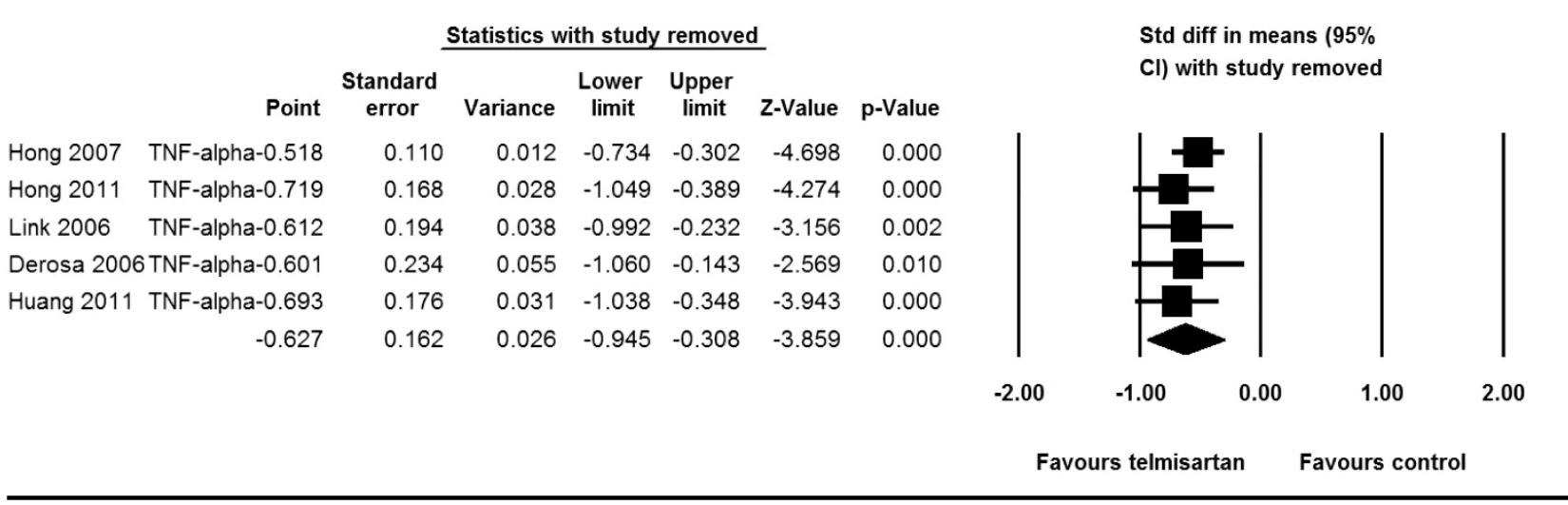

Figure 4 One-study-removed meta-analysis of percent changes in tissue necrosis factor-alpha (TNF- $\alpha$ ) levels among patients randomized to telmisartan vs. control therapy. $\mathrm{Cl}$, confidence interval.

Nagel et al. ${ }^{20}$ evaluated the effect of 12 weeks of telmisartan in subjects with insulin resistance in a randomized, placebo-controlled, double-blind, crossover study, and IL-6 concentrations were unchanged during telmisartan treatment compared with placebo $\left(1.80 \pm 1.02\right.$ vs. $\left.1.66 \pm 0.92 \mathrm{pg} \mathrm{dl}^{-1} ; \quad P=0.96\right)$. Wohl et al. ${ }^{21}$ evaluated the effect of telmisartan in a double-blind, randomized, crossover trial in which patients with impaired fasting glucose received telmisartan or a placebo for 3 weeks and vice versa with a 2-week washout period. During the hyperinsulinemic euglycemic clamp at the end of each period, TNF- $\alpha$ was decreased after telmisartan treatment $\left(7.4 \pm 0.9\right.$ vs. $\left.8.6 \pm 1.0 \mathrm{pg} \mathrm{dl}^{-1} ; P<0.05\right)$.

\section{Publication bias}

To assess publication bias, we generated a funnel plot of the logarithm of effect size vs. the standard error for each trial (data not shown). There was no evidence of significant publication bias $(P=0.764$ and 0.779 for IL-6; $P=1.000$ and 0.360 for TNF- $\alpha$; by the adjusted rankcorrelation and linear regression test, respectively).

\section{DISCUSSION}

The results of our analysis suggest that telmisartan therapy may reduce both IL- 6 and TNF- $\alpha$ levels over control therapy; this finding was robust in sensitivity analyses. On the basis of cellular assays of PPAR- $\gamma$ activation, Benson et al. ${ }^{7}$ have found that the angiotensin II receptor antagonist telmisartan is also a partial agonist of PPAR- $\gamma$, a well-known target of insulin-sensitizing drugs used to treat type 2 diabetes. In contrast, none of the other ARBs affected PPAR- $\gamma$ activity, with the possible exception of irbesartan, which appeared to cause a modest activation of the receptor. ${ }^{7}$

The meta-analysis by Riera-Guardia and Rothenbacher ${ }^{5}$ that included 19 studies examined the effect of the intake of thiazolidinedione, a PPAR- $\gamma$ agonist, ${ }^{6}$ on adiponectin serum concentrations in various subjects with different comorbidities. The thiazolidinedione treatment was clearly associated with an increase in adiponectin serum concentrations independent of the baseline population characteristics, and subjects treated with thiazolidinedione had average levels that were $\sim 1$ SD higher compared with the control group. ${ }^{5}$ Thus, telmisartan, a partial agonist of PPAR- $\gamma,{ }^{7}$ may increase adiponectin.

Indeed, we recently performed a meta-analysis of 11 randomized head-to-head trials (representing 1088 patients) and demonstrated a statistically significant increase in the percent changes of adiponectin levels (random-effects mean difference, 15.74\%; 95\% CI, 4.95-26.52\%; $P=0.004$ ) with telmisartan relative to other ARB therapy. ${ }^{8}$ There is an inverse correlation between plasma adiponectin and IL-6 concentrations. $^{23,24}$ Adiponectin and TNF- $\alpha$ mutually inhibit each other's production in adipose tissue, and adiponectin can counteract the proinflammatory effects of TNF- $\alpha$ in vascular cells. ${ }^{25-28}$ It has been observed that chronic administration of troglitazone, a selective ligand for PPAR- $\gamma$, is associated with a greatly attenuated responsiveness toward inducers of hepatic TNF- $\alpha$ and IL- 6 production. ${ }^{29}$ Additionally, IL-6 concentration is elevated in the plasma of diabetic rabbits and significantly diminished after treatment with pioglitazone, a high-affinity ligand of PPAR- $\gamma \cdot{ }^{30}$ Pioglitazone significantly reduces serum TNF- $\alpha$ levels in hypercholesterolemic rabbits independent of its metabolic actions, which may at least partly be due to its direct inhibition of TNF- $\alpha$ expression and secretion in adipocytes. ${ }^{31}$

These findings regarding PPAR- $\gamma$ agonists could explain the reduction in IL- 6 and TNF- $\alpha$ levels with telmisartan therapy demonstrated in the present meta-analysis. Tian et al. ${ }^{32}$ examined whether telmisartan inhibits the expression of IL-6 in vascular smooth muscle cells. Telmisartan, but not valsartan, attenuated IL-6 mRNA expression induced by TNF- $\alpha$. Because the suppression of IL-6 mRNA expression was prevented by pretreatment with a specific PPAR- $\gamma$ antagonist, PPAR- $\gamma$ may be involved in the process. Telmisartan also attenuated serum IL- 6 levels in TNF- $\alpha$-infused mice and IL- 6 production from rat aorta stimulated with TNF- $\alpha$ ex vivo.

These data suggest that telmisartan, but not valsartan, suppresses TNF- $\alpha$-induced IL-6 expression in a PPAR- $\gamma$-dependent manner. ${ }^{32}$ Furthermore, both IL- 6 and TNF- $\alpha$ are important pro-inflammatory adipokines that contribute to the regulation of CRP production in liver. $^{3}$ Our recent meta-analysis ${ }^{33}$ of 17 randomized controlled trials (representing 2632 patients) demonstrated a statistically significant reduction in percent changes of high-sensitivity CRP levels with telmisartan relative to control therapy (fixed-effects mean difference, $-10.80 \%$; $95 \%$ CI, $-16.15 \%$ to $-5.45 \%$; $P<0.0001$ ). Thus, telmisartan may reduce CRP via reducing IL- 6 and TNF- $\alpha$.

Recently, Barnabe et al. ${ }^{34}$ sought to systematically assess the association between anti-TNF- $\alpha$ therapy in rheumatoid arthritis and cardiovascular event rates. Anti- TNF- $\alpha$ therapy is associated with a reduced risk of all cardiovascular events, myocardial infarction, and cerebrovascular accident in observational cohorts. Although the point estimate of the effect from randomized controlled trials is 
underpowered with wide 95\% CIs, and cardiovascular events were secondary outcomes, randomized trials also demonstrated a trend toward decreased risk. ${ }^{32}$

Raised levels of markers of acute inflammatory response after stroke are associated with poor outcomes. The odds ratios (ORs) for the association of markers and poor outcome (comparing the upper and the lower third) were IL-6, 3.1 (95\% CI, 1.9-5.0); CRP, 1.9 (95\% CI, 1.2-3.1); fibrinogen, 1.5 (95\% CI, 1.0-2.36); white cell count, 2.1 (95\% CI, 1.3-3.4); and glucose, 1.3 (95\% CI, 0.8-2.1). ${ }^{35}$ In addition, long-term IL-6 levels are associated with coronary heart disease risk (OR per 2 SD increase in baseline IL-6, 1.61; 95\% CI, 1.42-1.83; OR per 2 SD increase in usual (long-term average) IL-6 levels, 3.34; 95\% CI, 2.45-4.56) approximately as strongly as are some major established risk factors, ${ }^{36}$ but causality remains uncertain. To determine whether unique properties of telmisartan are responsible for better clinical outcomes in cardiovascular disease prevention through the reductions in IL- 6 and TNF- $\alpha$, large clinical trials are needed.

In conclusion, we found that based on a meta-analysis of nine randomized controlled trials, telmisartan therapy is likely effective in reducing IL- 6 and TNF- $\alpha$ levels. The reduction of inflammatory cytokines by telmisartan shown in the present meta-analysis may be beneficial for the treatment of not only hypertension but also atherosclerotic cardiovascular diseases. However, large clinical trials are needed to determine whether these unique properties of telmisartan are responsible for better clinical outcomes in cardiovascular disease prevention.

\section{CONFLICT OF INTEREST}

The authors declare no conflict of interest.

1 Tilg $\mathrm{H}$, Wolf AM. Adiponectin: a key fat-derived molecule regulating inflammation. Expert Opin Ther Targets 2005; 9: 245-251.

2 Ouchi N, Kihara S, Funahashi T, Matsuzawa Y, Walsh K. Obesity, adiponectin and vascular inflammatory disease. Curr Opin Lipidol 2003; 14: 561-566.

3 Blake GJ, Ridker PM. Novel clinical markers of vascular wall inflammation. Circ Res 2001; 89: 763-771.

4 Hotamisligil GS, Shargill NS, Spiegelman BM. Adipose expression of tumor necrosis factor-alpha: direct role in obesity-linked insulin resistance. Science 1993; 259: 87-91.

5 Riera-Guardia N, Rothenbacher D. The effect of thiazolidinediones on adiponectin serum level: a meta-analysis. Diabetes Obes Metab 2008; 10: 367-375.

6 Spiegelman BM. PPAR-gamma: adipogenic regulator and thiazolidinedione receptor. Diabetes 1998; 47: 507-514.

7 Benson SC, Pershadsingh $\mathrm{HA}, \mathrm{Ho} \mathrm{Cl}$, Chittiboyina A, Desai P, Pravenec M, Qi N, Wang J, Avery MA, Kurtz TW. Identification of telmisartan as a unique angiotensin II receptor antagonist with selective PPARgamma-modulating activity. Hypertension 2004; 43: 993-1002.

8 Takagi H, Umemoto T. Telmisartan increases adiponectin levels: a meta-analysis and meta-regression of randomized head-to-head trials. Int J Cardiol 2012; 155: 448-451.

9 Higgins JP, Deeks JJ, Altman DG. Chapter 16: Special topics in statistics. In Higgins JP and Green S (eds). Cochrane Handbook for Systematic Reviews of Interventions Version 5.1.0 (updated March 2011) The Cochrane Collaboration, 2011, Available from www. cochrane-handbook.org.

10 Follmann D, Elliott P, Suh I, Cutler J. Variance imputation for overviews of clinical trials with continuous response. I Clin Epidemiol 1992; 45: 769-773.

11 Bähr IN, Tretter P, Krüger J, Stark RG, Schimkus J, Unger T, Kappert K, Scholze J, Parhofer KG, Kintscher U. High-dose treatment with telmisartan induces monocytic peroxisome proliferator-activated receptor- $\gamma$ target genes in patients with the metabolic syndrome. Hypertension 2011; 58: 725-732.

12 Derosa G, Cicero AF, D’Angelo A, Ragonesi PD, Ciccarelli L, Piccinni MN, Pricolo F, Salvadeo SA, Ferrari I, Gravina A, Fogari R. Telmisartan and irbesartan therapy in type 2 diabetic patients treated with rosiglitazone: effects on insulin-resistance, leptin and tumor necrosis factor-alpha. Hypertens Res 2006; 29: 849-856.

13 Hong SJ, Shim WJ, Choi JI, Joo HJ, Shin SY, Park SM, Lim SY, Lim DS. Comparison of effects of telmisartan and valsartan on late lumen loss and inflammatory markers after sirolimus-eluting stent implantation in hypertensive patients. Am J Cardiol 2007; 100: 1625-1629.
14 Hong SJ, Choi SC, Ahn CM, Park JH, Kim JS, Lim DS. Telmisartan reduces neointima volume and pulse wave velocity 8 months after zotarolimus-eluting stent implantation in hypertensive type 2 diabetic patients. Heart 2011; 97: 1425-1432.

15 Huang GZ, Tang YH, Wang BY, Zhang B, Hu TJ, Zhang L, Zhang XY, Zhong Y. Effects of telmisartan on insulin resistance and visceral fat distribution in Chinese hypertensive patients with obesity. Saudi Med J 2011; 32: 1017-1021.

16 Link A, Lenz M, Legner D, Böhm M, Nickenig G. Telmisartan inhibits beta2-integrin MAC-1 expression in human T-lymphocytes. J Hypertens 2006; 24: 1891-1898.

17 Nakamura T, Inoue T, Suzuki T, Kawagoe Y, Ueda Y, Koide H, Node K. Comparison of renal and vascular protective effects between telmisartan and amlodipine in hypertensive patients with chronic kidney disease with mild renal insufficiency. Hypertens Res 2008; 31: 841-850.

18 Nakamura T, Sato E, Fujiwara N, Kawagoe Y, Yamada S, Ueda Y, Koide H. Changes in urinary albumin excretion, inflammatory and oxidative stress markers in ADPKD patients with hypertension. Am J Med Sci 2012; 343: 46-51.

19 Nakayama S, Watada H, Mita T, Ikeda F, Shimizu T, Uchino H, Fujitani Y, Hirose T, Kawamori R. Comparison of effects of olmesartan and telmisartan on blood pressure and metabolic parameters in Japanese early-stage type-2 diabetics with hypertension. Hypertens Res 2008; 31: 7-13.

20 Nagel JM, Tietz AB, Göke B, Parhofer KG. The effect of telmisartan on glucose and lipid metabolism in nondiabetic, insulin-resistant subjects. Metabolism 2006; 55 : 1149-1154

21 Wohl P, Krusinová E, Hill M, Kratochvílová S, Zídková K, Kopecký J, Neskudla T, Pravenec M, Klementová M, Vrbíková J, Wohl P, Mlejnek P, Pelikánová T. Effect of telmisartan on selected adipokines, insulin sensitivity, and substrate utilization during insulin-stimulated conditions in patients with metabolic syndrome and impaired fasting glucose. Eur J Endocrinol 2010; 163: 573-583.

22 Cadeddu C, Piras A, Mantovani G, Deidda M, Dessì M, Madeddu C, Massa E, Mercuro G. Protective effects of the angiotensin II receptor blocker telmisartan on epirubicininduced inflammation, oxidative stress, and early ventricular impairment. Am Heart $J$ 2010; 160: e1-e7.

23 Esposito K, Pontillo A, Di Palo C, Giugliano G, Masella M, Marfella R, Giugliano D. Effect of weight loss and lifestyle changes on vascular inflammatory markers in obese women: a randomized trial. JAMA 2003; 289: 1799-1804.

24 Krakoff J, Funahashi T, Stehouwer CD, Schalkwijk CG, Tanaka S, Matsuzawa Y, Kobes S, Tataranni PA, Hanson RL, Knowler WC, Lindsay RS. Inflammatory markers, adiponectin, and risk of type 2 diabetes in the Pima Indian. Diabetes Care 2003; 26: 1745-1751.

25 Maeda N, Shimomura I, Kishida K, Nishizawa H, Matsuda M, Nagaretani H, Furuyama N, Kondo H, Takahashi M, Arita Y, Komuro R, Ouchi N, Kihara S, Tochino Y, Okutomi K, Horie M, Takeda S, Aoyama T, Funahashi T, Matsuzawa Y. Diet-induced insulin resistance in mice lacking adiponectin/ACRP30. Nat Med 2002; 8: 731-737

26 Matsuda M, Shimomura I, Sata M, Arita Y, Nishida M, Maeda N, Kumada M, Okamoto Y, Nagaretani $H$, Nishizawa $H$, Kishida $K$, Komuro $R$, Ouchi $N$, Kihara S, Nagai $R$, Funahashi T, Matsuzawa Y. Role of adiponectin in preventing vascular stenosis. The missing link of adipo-vascular axis. J Biol Chem 2002; 277: 37487-37491.

27 Ouchi N, Kihara S, Arita Y, Maeda K, Kuriyama H, Okamoto Y, Hotta K, Nishida M, Takahashi M, Nakamura T, Yamashita S, Funahashi T, Matsuzawa Y. Novel modulator for endothelial adhesion molecules: adipocyte-derived plasma protein adiponectin. Circulation 1999; 100: 2473-2476.

28 Yokota T, Oritani K, Takahashi I, Ishikawa J, Matsuyama A, Ouchi N, Kihara S, Funahashi T, Tenner AJ, Tomiyama Y, Adiponectin MatsuzawaY. a new member of the family of soluble defense collagens, negatively regulates the growth of myelomonocytic progenitors and the functions of macrophages. Blood 2000; 96: 1723-1732.

29 Sigrist S, Bedoucha M, Boelsterli UA. Down-regulation by troglitazone of hepatic tumor necrosis factor-alpha and interleukin-6 mRNA expression in a murine model of noninsulin-dependent diabetes. Biochem Pharmacol 2000; 60: 67-75.

30 Gumieniczek A, Hopkała H, Roliński J, Bojarska-Junak A. Interleukin-6 and oxidative stress in plasma of alloxan-induced diabetic rabbits after pioglitazone treatment. Immunopharmacol Immunotoxicol 2006; 28: 81-91.

$31 \mathrm{Wu}$ ZH, Zhao SP, Chu LX, Ye HJ. Pioglitazone reduces tumor necrosis factor-alpha serum concentration and mRNA expression of adipose tissue in hypercholesterolemic rabbits. Int J Cardiol 2010; 138: 151-156.

32 Tian Q, Miyazaki R, Ichiki T, Imayama I, Inanaga K, Ohtsubo H, Yano K, Takeda K, Sunagawa K. Inhibition of tumor necrosis factor-alpha-induced interleukin-6 expression by telmisartan through cross-talk of peroxisome proliferator-activated receptorgamma with nuclear factor kappaB and CCAAT/enhancer-binding protein-beta. Hypertension 2009; 53: 798-804.

33 Takagi H, Yamamoto H, Iwata K, Goto SN, Umemoto T. Effects of telmisartan on C-reactive protein levels: A meta-analysis of randomized controlled trials. Int J Cardiol 2012; 156: 238-241.

34 Barnabe C, Martin BJ, Ghali WA. Systematic review and meta-analysis: anti-tumor necrosis factor $\alpha$ therapy and cardiovascular events in rheumatoid arthritis. Arthritis Care Res (Hoboken) 2011; 63: 522-529.

35 Whiteley W, Jackson C, Lewis S, Lowe G, Rumley A, Sandercock P, Wardlaw J, Dennis $M$, Sudlow C. Inflammatory markers and poor outcome after stroke: a prospective cohort study and systematic review of interleukin-6. PLoS Med 2009; 6: e1000145.

36 Danesh J, Kaptoge S, Mann AG, Sarwar N, Wood A, Angleman SB, Wensley F, Higgins JP, Lennon L, Eiriksdottir G, Rumley A, Whincup PH, Lowe GD, Gudnason V. Long-term interleukin- 6 levels and subsequent risk of coronary heart disease: two new prospective studies and a systematic review. PLoS Med 2008; 5: e78. 